\title{
Bio/adsorção de íons metálicos em soluções aquosas diluídas utilizando bio/adsorventes alternativos: estudo de afinidade metálica
}

\author{
Hellen da Costa*, Yasmim S. Silva*, Juliana Bonatti*, Talles B. Costa, Welenilton J. N. Junior, Meuris, G. C. Silva, \\ Melissa G. A. Vieira
}

\section{Resumo}

O objetivo deste estudo foi avaliar a bioadsorção de íons prata e cobre em coluna de leito fixo, empregando-se o resíduo da extração de algas e avaliar o pontencial das partículas de sericina e alginato para recuperar os íons terrasraras lantânio, cério e neodímio, através de ensaios de afinidade metálica. Os resultados mostraram que os íons cobre levaram mais tempo para alcançar a ruptura em relação a prata e as partículas de sericina e alginato reticuladas com éter polietilenoglicol diglicídio apresentaram maior afinidade pelos íons terras-raras.

\section{Palavras-chave:}

Bioadsorção, íons metálicos, afinidade metálica

\section{Introdução}

A sericina é uma proteína hidrossolúvel, descartada no processamento do casulo do bicho da seda (Bombyx mori), e o alginato é um polissacarídeo presente na parede celular de algas marrons, muito abundantes na costa brasileira. Ambos são polímeros que habilitam seu uso na produção de biomateriais, como as partículas de blenda entre sericina e alginato e o resíduo da extração de alginato de algas marrons, empregados em processos de bioadsorçãa[ [1].

Dessa forma, o objetivo deste trabalho foi avaliar a bioadsorção binária entre prata $\left(\mathrm{Ag}^{+}\right)$e cobre $\left(\mathrm{Cu}^{2+}\right)$, utilizado o resíduo da extração do alginato da alga Sargassum filipendula como bioadsorvente em sistema dinâmico. Além disso, foi estudado o potencial de bioadsorção das partículas produzidas a partir da blenda entre sericina, alginato com éter polietilenoglicol diglicídio (SAPEG) e proantocianidinas (SAPAs), por meio de testes de afinidade metálica com os íons terras-raras lantânio $\left(\mathrm{La}^{3+}\right)$, cério $\left(\mathrm{Ce}^{3+}\right)$ e neodímio $\left(\mathrm{Nd}^{3+}\right)$.

\section{Resultados e Discussão}

A Figura 1 apresenta as curvas de ruptura para a $\mathrm{Ag}^{+} \mathrm{e}$ $\mathrm{Cu}^{2+}$.

Figura 1. Curvas de ruptura da bioadsorção de íons prata e cobre em mistura binária.

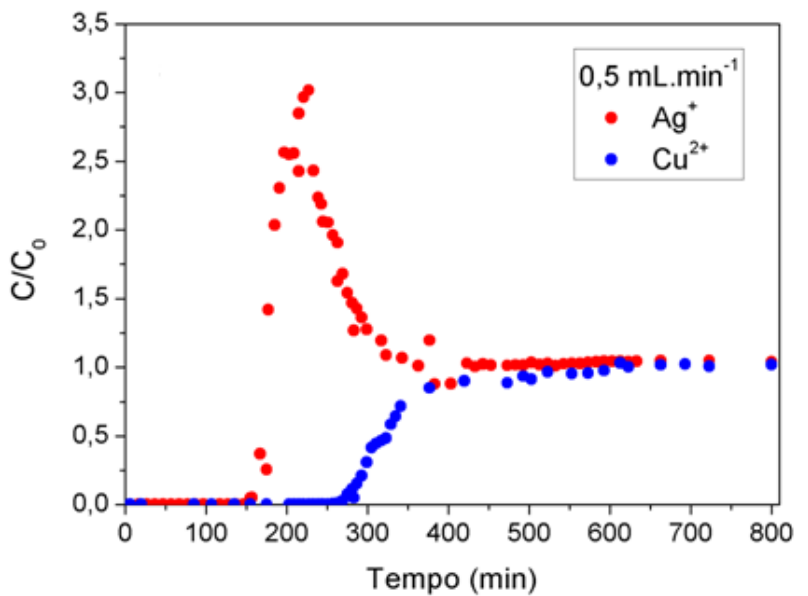

De acordo com o gráfico, observa-se que o $\mathrm{Cu}^{2+}$ leva mais tempo até atingir a ruptura em relação a prata, pois o $\mathrm{Cu}^{2+}$ apresentou maior afinidade com o resíduo. Esse fenômeno é chamado de overshoot e representa a troca iônica dos íons $\mathrm{Ag}^{+}$adsorvidos pelos íons $\mathrm{Cu}^{2+}$.

Os testes de afinidade metálica, por sua vez, foram realizados com o objetivo de avaliar a afinidade metálica entre os íons terras-raras $\mathrm{La}^{3+}, \mathrm{Ce}^{3+}$ e $\mathrm{Nd}^{3+} \mathrm{e}$ as partículas de SAPEG e SAPAs..

Tabela 1. Afinidade metálica dos íons terras-raras e as partículas de SAPEG e SAPAs.

\begin{tabular}{|l|c|c|c|c|}
\hline \multirow{2}{*}{ Partícula } & $\begin{array}{c}\mathrm{C}_{0} \\
(\mathrm{mmol} / \mathrm{L})\end{array}$ & $\begin{array}{c}\mathrm{q}_{\mathrm{e}} \\
(\mathrm{mmol} / \mathrm{g})\end{array}$ & $\begin{array}{c}\mathrm{Ce}^{3+} \\
(\mathrm{mmol} / \mathrm{g})\end{array}$ & $\begin{array}{c}\mathrm{Nd}^{3+} \\
(\mathrm{mmol} / \mathrm{g})\end{array}$ \\
\hline \multirow{2}{*}{ SAPEG } & 1,0 & 0,096 & 0,103 & 0,101 \\
\cline { 2 - 5 } & 3,0 & 0,277 & 0,291 & 0,293 \\
\hline \multirow{2}{*}{ SAPAs } & 1,0 & 0,095 & 0,102 & 0,101 \\
\cline { 2 - 5 } & 3,0 & 0,243 & 0,263 & 0,260 \\
\hline
\end{tabular}

Pela Tabela 1, verifica-se que ambas as partículas apresentaram alta afinidade pelos íons terras-raras $\mathrm{La}^{3+}$, $\mathrm{Ce}^{3+}$ e $\mathrm{Nd}^{3+}$, na concentração inicial de $1,0 \mathrm{mmol} \mathrm{L}^{-1}$, sendo observada elevada porcentagem de remoção e capacidade de adsorção. Para os ensaios em concentração inicial de $3,0 \mathrm{mmol} \mathrm{L}^{-1}$, foi possível observar que as partículas de SAPEG apresentaram maior afinidade pelos íons terras-raras $\mathrm{La}^{3+}, \mathrm{Ce}^{3+} \mathrm{e} \mathrm{Nd}^{3+}$.

\section{Conclusões}

A utilização do resíduo da extração de alginato da alga $S$. filipendula apresentou resultados eficientes para ambos componentes da mistura binária de $\mathrm{Ag}^{+} \mathrm{e} \mathrm{Cu}^{2+}$. Os íons terras-raras apresentaram alta afinidade para ambas as partículas. Os resultados obtidos indicam um potencial uso das partículas de SAPEG para a remoção dos íons terras-raras $\mathrm{La}^{3+}, \mathrm{Ce}^{3+}$ e $\mathrm{Nd}^{3+}$.

\section{Agradecimentos}

Os autores agradecem ao CNPq e FAPESP (Proc. 2017/18236-1) pelo apoio financeiro, e à empresa BRATAC pelo fornecimento dos casulos.

${ }^{1}$ SILVA, T. L., SILVA JUNIOR, A. C., VIEIRA, M. G. A., GIMENES, M. L., SILVA M. G. C. Production and Physicochemical Characterization of Microspheres Made from Sericin and Alginate Blend. Chemical Engineering Transactions, V. 39, p. $643-648,2014$. 